\title{
Using motivational interviewing techniques to inform decision-making for COVID-19 vaccination
}

\author{
Monica Zolezzi ${ }^{1}\left[\right.$ ] Bridget Paravattil $^{1} \cdot$ Taysier El-Gaili $^{2}$
}

Received: 15 July 2021 / Accepted: 18 September 2021 / Published online: 2 October 2021

(c) The Author(s), under exclusive licence to Springer Nature Switzerland AG 2021

\begin{abstract}
Motivational interviewing is a patient-centered communication style used to enhance a person's internal motivation for attitudinal change by exploring and solving inherent ambivalences. In the face of rising COVID-19 vaccine hesitancy, pharmacists and other health care professionals may use motivational interviewing to enable individuals making informed decisions with regards to the COVID-19 vaccines. The purpose of this article is to integrate theory with practice by describing a scenario that illustrates how motivational interviewing skills and strategies can be used to reduce COVID-19 vaccine hesitancy.
\end{abstract}

Keywords COVID-19 vaccine $\cdot$ Hesitancy $\cdot$ Motivational interviewing

\section{Impacts on practice}

- Pharmacists are well positioned to improve people's understanding of the COVID19 vaccine and influence on decision-making among those who are vaccine-hesitant.

- While educating the public, pharmacists can use motivational interviewing techniques to explore people's ambivalence regarding the COVID-19 vaccine.

\section{Background}

Vaccination programs have contributed substantially to the decline in mortality and morbidity of infectious diseases [1]. The coronavirus disease pandemic that emerged in 2019 (COVID-19) continues to impact all aspects of life worldwide from countless lives being lost to the cause of unprecedented social distress. Although several strategies have been implemented to tackle the spread of this infection, vaccination as opposed to natural infection offers the most

Monica Zolezzi

mzolezzi@qu.edu.qa

1 College of Pharmacy, QU Health, Qatar University, Doha, Qatar

2 College of Medicine, Qatar University, Doha, Qatar viable and optimistic option in achieving herd immunity [2, 3].

Vaccine hesitancy, defined by the World Health Organization (WHO) as the "delay in acceptance or refusal of vaccines, despite availability of vaccine services", is within the top ten global health threats of 2019 [4-6]. Despite the promising efficacy and safety of COVID-19 vaccines, many continue to remain opposed to getting vaccinated [7]. Educational strategies that focus not only on increasing the public's knowledge and awareness, but also that evoke health behaviour change, have been recommended to decrease vaccine hesitancy [4, 5, 8, 9]. Motivational interviewing (MI) is a patient-centered communication style used to enhance a person's internal motivation for attitudinal change by exploring and solving inherent ambivalences [10]. Evidence suggests that pharmacists are well positioned to utilize the MI approach to help people overcome ambivalence towards immunizations [11-13].

The underlying framework, often referred to as the "spirit" of MI, is based on partnership, acceptance, compassion, and autonomy [14]. The goal is to engage the person in a collaborative working relationship, allowing the individual to feel involved in the decision to change within a respectful and non-judgmental atmosphere, and to resist the urge to dictate the problem and the solution. As outlined in Table 1, the core communication skills consistent with the spirit of MI that are used by practitioners to build rapport and establish a therapeutic relationship with patients 
Table 1 Interviewing techniques used in motivational interviewing

OARS
Open-ended questioning: These type of questions cannot be
answered with "yes" or "no" statements. Posing a question that
provides an opportunity for the individual to craft a response so that
clinicians understand his/her perception of the issue being discussed
Example:
"I understand you have some concerns about the COVID19 vaccines.
Can you tell me about them?"
Versus:
"Are you concerned about getting vaccinated?"

\begin{abstract}
Affirming: Acknowledging the person's strengths and offering encouragement towards a change goal. This helps to build rapport and fosters confidence in the person's ability to change behavior Example:

"You have clearly been very resourceful coping with the difficulties during the COVID19 pandemic."
\end{abstract}

Reflective listening: Involves rephrasing a statement made by the person to better understand his/her perceptions. By having the person hear his or her thoughts and feelings in a different format supports internal motivation to change

Example:

"I can definitely relate to your concerns ... and I do agree with you that there is a lot of conflicting information out there."

\footnotetext{
Summarizing: Although it is used mostly at the end to close the session and to ensure the information gathered is mutually understood, summarizing can also be used to link statements together, at the beginning or during the MI session, collecting the individual's change talk statements, inviting him/her to tell more by asking "what else"

Example:

"So you are saying that if you get vaccinated you fear you might experience an allergic reaction similar to the ones you experienced as a result of eating peanuts."
}

Change talk

Displaying empathy: Involves a partnership and consultation with the individual, honoring his/her expertise and perspectives, whereby the atmosphere is conducive rather than coercive to change. In this phase, "change talk" is initiated by listening more than telling, eliciting rather than installing, so that intrinsic motivation for change is enhanced by drawing on the individual's own perceptions, goals, and values. A simple way to do that is to:

Use reflective listening skills to accurately portray empathy

Create open and respectful exchange with the individual

Avoid judging, criticizing or blaming the individual

Developing discrepancy: Guiding the individual to be aware of his/her current status, and where he/she would like to be in the near future, examining readiness for change by:

Helping the individual to explore the pros and cons of change

Developing disagreement in their presentation of their "facts"

Developing awareness of the consequences of their behavior

Rolling with resistance: Identifying the individual's resistance and responding with support may minimize ambivalence and offer insight into the individual's internal challenges. Resistance may be displayed as: Interrupting, arguing, ignoring, excusing behavior, blaming others, being pessimistic, unwillingness to change. Approach resistance without judgement, by:

Shifting focus: get away from the difficult topic

Reframing what the individual said

Reflecting on what it is said and re-direct

Supporting self-efficacy: Increasing the individual's confidence of their ability to make a change, by instilling hope and empowering them, by:

Focusing on their strengths and approaches they have used in the past to make changes

Utilizing examples of individuals in similar situations who have been successful in making a change

Educating them with accurate and reliable information to them process and understand the situation to make changes to achieve the intended outcome or goal

\section{Importance/Confidence Ruler:}

On a scale from 1 to 10, with 1 being not at all important and 10 being extremely important: How important is it for you to make this change?

On a scale from 1 to 10 with 1 being not at all confident and 10 being extremely confident: How confident are you that you could make this change?

are represented by the acronym OARS: Open questioning, Affirming, Reflective listening, and Summarizing [10]

MI has traditionally been employed with people who are experiencing ambivalence or resistance toward behavioral change and are disengaging from treatment services. Thus, eliciting "change talk" is an important aspect of MI, as it is a consciously directive strategy used for resolving ambivalence. This guiding style is preferred over the authoritative, practitioner-led strategy of educating, advising, or convincing, which can have the opposite effect resulting in further resistance and defiance from the individual [10]. As outlined in Table 1, change talk involves 4 steps: Displaying empathy, developing discrepancy, rolling with resistance, and supporting self-efficacy. Changing attitudes and behaviours or adopting new ones depend on how important the change is to the individual as well as how confident and prepared they are in adopting change. Using the "importance/confidence ruler" also facilitates change talk and allows practitioners to learn about facilitators and barriers to guide the individual towards change and make it easier to tailor an appropriate action plan. In this article a case vignette is used to illustrate a common scenario and how the pharmacist can use MI to increase knowledge, reduce perceived misconceptions, change attitudes, and enable informed decision-making with regards to the COVID-19 vaccines.

\section{Case vignette}

A pharmacist working in a community pharmacy is approached by Mrs. VD, a 54 year-old teacher working at a local international school. She asks the pharmacist for vitamin $\mathrm{D}$, zinc, vitamin $\mathrm{C}$, and ivermectin. When asked the 
reason for requesting these products, Mrs. VD states she is using them to prevent COVID-19.

Pharmacist (Rx): "Hi Ms. VD ...How are you doing today?" [OARS: Open questioning]

Mrs. VD: "Barely managing with this pandemic!" Rx: "You seem to be handling it well; I can see you wearing your mask, you're pretty conscious about the distance... Well done!" [OARS: Affirmation]

Mrs. VD: "Yeah, but it seems endless..."

$\mathrm{Rx}$ : "Indeed. Everyone suffered in one way or another but there seems to be optimism and hope to get our lives back now that the COVID vaccines are available. Have you been vaccinated yet?" [OARS: Affirmation; Change Talk: Displaying empathy]

Mrs. VD: "No! Not me! I'm not going to get vaccinated. It's not safe, plus I have allergies. These vaccines are still undergoing trials. They were made so quickly! No one knows what side effects they can cause! I'm good with my natural supplements."

$\mathrm{Rx}$ : "I can definitely relate to your concerns, there is a lot of conflicting information out there. I heard you mentioning some concerns about the COVID vaccine because of your allergies. Can you tell me more about your allergies?" [OARS: Affirmation, Reflective Listening; Open questioning; Change Talk: Rolling with resistance]

Mrs. VD: "Well, since early childhood I have been allergic to peanuts. Apparently, my mom got scared because I developed a skin rash and my lips started swelling after eating chocolate with peanuts."

$\mathrm{Rx}$ : "Did you have a similar reaction in adulthood? How have you managed this allergy before?" [OARS: Open questioning; Change Talk: Developing discrepancy]

Mrs. VD: "Not in adulthood, as I was taught to read food labels and always identify myself as allergic to nuts. Sometimes, I take an antihistamine if I suspect something I took had nuts. I also carry an epinephrine injection with me, just in case! I also have seasonal allergies every Spring, with mostly nasal congestion that I treat with loratadine.

Rx: "I imagine you are up-to-date on your immunizations. Did you experience any reactions to any of the vaccines you had in the past?" [OARS: Affirmation; Change Talk: Developing discrepancy]

Mrs. VD: "I (and my kids) had all recommended childhood immunizations. We did not experience any reactions. But this COVID vaccine, I read it is not safe for people with allergies. I rather take vitamins to boost my immune system."

Rx: "Your concerns are valid. If I had experienced an allergic reaction to peanuts as you had in the past, I would be worried myself of experiencing an allergic reaction to the vaccine. So, because of that fear you prefer to boost your immunity against COVID with vitamins. Can you tell me more about what you know about vitamin $D$, zinc, vitamin $C$, and ivermectin protecting you against COVID19?" [OARS: Affirmation, Reflective listening, Summarizing; Open questioning; Change Talk: Developing discrepancy]

Mrs. VD: "I always used vitamin $C$ when I had a cold to help me recover. I also heard that people with low levels of vitamin $D$ are more likely to die if they are infected with COVID-19. I understand that zinc is an antioxidant and thus protects against some toxins released by the virus, and that ivermectin prevents you from getting infected."

$\mathrm{Rx}$ : "I agree that these vitamins have properties that can boost the immune system. The World Health Organization states that only the vaccine will be able to protect us from getting seriously ill with COVID19. What do you think?" [OARS: Open questioning; Change Talk: Rolling with resistance, Developing discrepancy]

Mrs. VD: "Well, on one hand I feel I should get vaccinated and get back to a normal life, and on the other hand, I'm worried if it is safe."

Rx: "You sound like you don't know what to do. What would be the worst scenario if you get vaccinated?"

[OARS: Affirming, Open questioning; Change Talk: Rolling with resistance, Developing discrepancy] Mrs. VD: "I fear experiencing a severe allergic reaction. But, I have also heard that people won't be able to travel if they don't get vaccinated! That would be really hard for me!"

Rx: "I have heard that too! So, on a scale from 1 to 10, 1 being not important at all and 10 being extremely important, how important is it to you to travel and go back to life how it was before COVID19." [OARS: Affirming, Open questioning; Change Talk: Importance ruler]

Mrs. VD: "I guess a 7. It is not just the traveling. Being able to socialize, having a meal with friends, going to the gym, or even go to work...I really don't like online teaching."

$\mathrm{Rx}$ : "It seems rather important to you to get your life back! And sounds like the vaccine may facilitate this... but your history of allergies is coming in the way of you taking the vaccine.?

Tell me what you know about the allergic reactions caused by COVID vaccine." [OARS: Affirming, Summarizing, Open questioning; Change Talk: Rolling with resistance, Developing discrepancy]

Mrs. VD: "I just heard that people with allergies like me have died when taking the vaccine." 
Rx: "What I have learned is that the probability of dying as a consequence of the COVID19 infection is significantly more likely than experiencing a lifethreatening reaction to the vaccine. Did you know that people are monitored for 15-30 minutes after receiving the vaccine? Severe allergic reactions mostly occur within this timeframe. If you agree, I can provide you with a printout of the ingredients found in all currently available vaccines. You mentioned that you read food labels and carry around an epinephrine pen to protect yourself against any allergic reactions. How do you feel about using these approaches for the vaccine?"

[OARS: Affirming, Summarizing, Open questioning; Change Talk: Supporting self-efficacy]

Mrs. VD: "I like the idea about carrying the epinephrine pen with me if I decide on getting vaccinated."

$\mathrm{Rx}$ : "I have other patients with allergies similar to yours who have taken the vaccine without any reactions. He told me he was able to get on a plane to Dubai to see his grandkids, he was so happy!" [OARS: Summarizing; Change Talk: Supporting self-efficacy]

Mrs. VD: "Really? That gives me hope! I will consult my doctor before I make an appointment at the primary care clinic, so that all are aware of my allergies at the time of the vaccination."

$\mathrm{Rx}$ : "Do you have anyone who can further support you in this process?"[OARS: Open questioning, Summarizing; Change Talk: Supporting self-efficacy]

Mrs. VD: "I will ask my husband to accompany me to the appointment."

Rx: "Sounds like a good plan! Please let me know when you get an appointment. I would like to follow up with you after your first vaccine dose. I also must mention that after being fully vaccinated it is important that you continue to wear your mask in public places and engage in proper hand hygiene." [OARS: Summarizing; Change Talk: Supporting self-efficacy] Mrs. VD: "Really? But, what is the point of getting vaccinated then?"
Rx: "We are learning new things about the virus every day. Therefore, it is vital that we continue to protect ourselves and others whether or not we are vaccinated. It is important to continue with the preventative measures until we are able to get everyone vaccinated to stop the spread of the virus." [OARS: Affirming, Summarizing; Change Talk: Rolling with resistance, Supporting self-efficacy]

Mrs. VD: "Thank you for relieving my safety concerns over the COVID vaccine."

$\mathrm{Rx}$ : "Thank you for sharing your concerns about the COVID19 vaccine and for allowing me to discuss with you what I know"

\section{Tips for providers}

The case vignette presented illustrates how pharmacists may use the MI approach to communicate with those who are hesitant to take the COVID-19 vaccine. The focus should revolve around collaboration, drawing on their personal beliefs by listening to their fears, thoughts, and opinions. Time constraints has been reported as a main barrier to using MI in community practice $[13,15]$. Brief interventions based on MI may be a simpler alternative, where the aim is starting a conversation by using mostly open questions and empathic listening statements. A question as simple as "What are your personal health and safety goals around COVID-19 and this pandemic?" is a good starting point $[9,16]$

Staying current with the myths surrounding the COVID19 vaccine is almost as important as staying up to date on the evidence on vaccine efficacy and safety [2, 7, 9, 16-19]. Current conspiracy theories over-emphasize on the risks associated with the vaccine itself rather than on those related the COVID-19 illness. Studies exploring attitudes towards COVID-19 vaccines undertaken in several countries report the safety of the vaccine as the most prominent reason for vaccine hesitancy [20-23]. Table 2 provides evidence-based information to respond to the most common myths and concerns about the COVID-19 vaccines. 
Table 2 Common myths about the COVID-19 vaccines

Myths
The vaccine is too new and was rushed in the development and
approval processes

The vaccine will alter my DNA

I will react to the vaccine because I have allergies

\section{If I am vaccinated, I will test positive for COVID-19 and can infect others}

We don't know what is in the COVID-19 vaccine

What's the point of vaccination if I can still get the virus and need to continue wearing a mask

I can prevent COVID-19 by boosting my immune system with vitamins $C$ and $D$, and zinc

Ivermectin can prevent COVID-19 infection

The vaccine causes deadly blood clots

The vaccine may affect my changes to get pregnant

I am pregnant, harmful substances in the vaccine could affect the baby
Dispelling evidence

The concept of using mRNA as a novel therapeutic tool dates to the early 1990s [24]. Vaccine safety monitoring systems exist and are tasked to continuously identifying adverse events not encountered in clinical trials $[18,25]$

The mRNA is not designed to integrate with host DNA, nor can it typically do so given its rapid degradation. In the COVID-19 vaccine, once the immune response is initiated against the spike protein, mRNA is degraded by the cells [17-19,25]

Severe allergic reactions are rare, with an estimated rate of 11 cases per million doses of the vaccine $[26,27]$. As a result, post-vaccination observation has been made mandatory: $30 \mathrm{~min}$ for those with a history of severe allergic reactions and $15 \mathrm{~min}$ for everyone else [17, 18, $25]$. Some of the vaccines have polyethylene glycol, which has been implicated in some of the allergic responses to the vaccine [28]

The COVID-19 vaccine does not contain the live virus, and vaccines are unable to trigger the full disease. An individual who has received the vaccine will not test positive for COVID-19 in the absence of infection $[18,25]$

The ingredients for the majority of the currently used vaccines have been published [29]. Vaccines usually contain lipids that help deliver the mRNA into the cells and other common ingredients that help maintain the $\mathrm{pH}$ and stability of the vaccine [28]. Despite theories circulated on social media, they do not contain microchips or any form of tracking device [17]

The COVID-19 vaccines were tested for their ability to prevent severe illness and death from COVID-19 [17]. It is not clear whether they also protect against asymptomatic infection and spread. As such, even after being fully vaccinated, it is important to keep wearing a mask around others, washing hands and practicing physical distancing [17, 30]

A few clinical trials have explored the possibility that supplements may be effective in COVID-19. Unfortunately, most of the scientific evidence is unconvincing $[31,32]$. The researchers found that people receiving the supplements, whether individually or combined, had no improvement in symptoms or a faster recovery when compared with otherwise similar patients receiving neither supplement

Ivermectin tablets are only approved to treat people with intestinal infections caused by parasitic worms. There are currently insufficient data to support use of ivermectin in COVID-19 patients to treat or to prevent COVID-19. In addition, it can interact with other medications and potentially cause harm [33]

Published estimates of the risk of vaccine-induced thrombotic thrombocytopenia (VITT) from countries with moderate to high data quality range from 1 case per 26,500 to 1 case per 127,300 first doses of AstraZeneca/COVISHIELD administered [34]. The European Medicines Agency states that this side effect is very rare, and that the overall benefits of the vaccine in preventing COVID-19 outweigh the risks of VITT [35]

Getting the COVID-19 vaccine will not affect the fertility of women who are seeking to become pregnant, including through in vitro fertilization methods [36]. Also, women trying to become pregnant do not need to avoid pregnancy after receiving a COVID-19 vaccine [37]

Studies have shown that pregnant women have an increased risk of getting severely ill if contracting COVID-19 [38, 39]. Studies have also shown that pregnant women who experience severe COVID-19 symptoms have a higher risk of complications during and after pregnancy $[39,40]$. A recent study reported that adverse outcomes occurred at similar rates in vaccinated women as those that occurred in other studies of unvaccinated women [41] 
Table 2 (continued)

\begin{tabular}{ll}
\hline Myths & Dispelling evidence \\
\hline $\begin{array}{l}\text { I breastfeeding, harmful substances in the vaccine could be passed to } \\
\text { my baby in the breast milk }\end{array}$ & $\begin{array}{c}\text { Several professional societies suggest that the vaccine can be taken dur- } \\
\text { ing breastfeeding as it is not thought to pose a risk to the breastfeeding } \\
\text { infant [42]. Recent reports have shown that breastfeeding people who } \\
\text { have received COVID-19 mRNA vaccines have antibodies in their } \\
\text { breastmilk, which could help protect their babies [37, 42] }\end{array}$
\end{tabular}

Funding The authors received no financial support for the authorship, and/or publication of this article.

\section{Declaration}

Conflicts of interest The authors declare no potential conflicts of interest with respect to the authorship and/or publication of this article.

\section{References}

1. Centers for Diseases Control and Prevention. Ten great public health achievements worldwide, 2001-2010. MMWR Morb Mortal Wkly Rep. 2011;60:814-8.

2. Dermody TS, DiMaio D, Enquist LW. Vaccine safety, efficacy, and trust take time. Annu Rev Virol. 2020; Nov 13. https://doi.org/10. 1146/annurev-vi-08-102220-100001.

3. Majeed A, Molokhia M. Vaccinating the UK against covid-19. BMJ. 2020; 371:m4654.

4. Strategic Advisory Group of Experts on Immunization (SAGE). Report of the SAGE Working Group on Vaccine Hesitancy. Geneva: WHO; 2014. www.who.int/immunization/sage/meeti ngs/2014/october/SAGE_working_group_revised_report_vacci ne_hesitancy.pdf?ua=1. Accessed 20 May 2021.

5. MacDonald NE. Vaccine hesitancy: definition, scope and determinants. Vaccine. 2015;33:4161-4.

6. World Health Organization. Ten threats to global health in 2019. https://www.who.int/news-room/spotlight/ten-threats-to-globalhealth-in-2019. Accessed 20 May 2021.

7. Markovitz G, Russo A. Survey shows rising vaccine hesitancy threatening COVID-19 recovery. World Economic Forum 2020. https://www.weforum.org/press/2020/11/survey-shows-risingvaccine-hesitancy-threatening-covid-19-recovery/. Accessed 20 May 2021.

8. Eskola J, Duclos P, Schuster M, MacDonald NE. SAGE Working Group on Vaccine Hesitancy. How to deal with vaccine hesitancy? Vaccine. 2015;33(34):4215-7.

9. World Health Organization. Regional office for Europe. Communicating with patients about COVID-19 vaccination. https://apps. who.int/iris/bitstream/handle/10665/340751/WHO-EURO-20212281-42036-57837-eng.pdf. Accessed 29 August 2021.

10. Rollnick S, Miller WR, Butler CC. Motivational interviewing in health care. Helping patients change behavior. New York: The Guilford Press; 2008. ISBN: 978-1593856120

11. Coley KC, Gessler C, McGivney M, Richardson R, DeJames J, Berenbrok LA. Increasing adult vaccinations at a regional supermarket chain pharmacy: A multi-site demonstration project. Vaccine. 2020;38(24):4044-4049.

12. Brackett A, Butler M, Chapman L. Using motivational interviewing in the community pharmacy to increase adult immunization readiness: A pilot evaluation. J Am Pharm Assoc. 2015;55(2):182-6.
13. Söderlund LL, Nilsen P. Feasibility of using motivational interviewing in a Swedish pharmacy setting. Int J Pharm Pract. 2009;17(3):143-9.

14. Miller WR, Rollnick S. Motivational interviewing: Preparing people for change (3rd ed.). London, UK: Guilford Press; 2013. ISBN: 978-1-60918-227-4.

15. Abughosh S, Wang X, Serna O, Esse T, Mann A, Masilamani $\mathrm{S}$, et al. A motivational interviewing intervention by pharmacy students to improve medication adherence. J Manag Care Spec Pharm. 2017;23(5):549-560.

16. Butler L. COVID-19 provides opportunity to rethink vaccine hesitancy. Pharmacy Today, May 2021. https://www.pharmacyto day.org/action/showPdf?pii=S1042-0991\%2821\%2900298-X. Accessed 30 August 2021.

17. Khawaja L, Iqbal S, Shah A, et al. Breaking the spell: Fighting myths about COVID-19 vaccination. Psychiatr Times. 2021;38(3):30-2.

18. Centers for Disease Control and Prevention. Myths and facts about COVID-19 vaccines [Internet]. Available online: https://www.cdc. gov/coronavirus/2019-ncov/vaccines/facts.html. Accessed 10 May 2021.

19. Montastruc JL, Lafaurie M, de Canecaude C, Montastruc F, Bagheri H, Durrieu G, et al. COVID-19 vaccines: a perspective from social pharmacology. Therapie. 2021;76(4):311-5.

20. Fisher KA, Bloomstone SJ, Walder J, Crawford S, Fouayzi H, Mazor KM. Attitudes toward a potential SARS-CoV-2 vaccine : A survey of U.S. adults. Ann Intern Med. 2020;173(12):964-973.

21. Sherman SM, Smith LE, Sim J, Amlôt R, Cutts M, Dasch H, et al. COVID-19 vaccination intention in the UK: results from the COVID-19 vaccination acceptability study (CoVAccS), a nationally representative cross-sectional survey. Hum Vaccin Immunother. 2021;17(6):1612-1621.

22. COCONEL Group. A future vaccination campaign against COVID-19 at risk of vaccine hesitancy and politicisation. Lancet Infect Dis. 2020; 20(7):769.

23. Alabdulla M, Reagu SM, Al-Khal A, Elzain M, Jones RM. COVID-19 vaccine hesitancy and attitudes in Qatar: A national cross-sectional survey of a migrant-majority population. Influenza Other Respir Viruses. 2021;15(3):361-370.

24. Verbeke R, Lentacker I, De Smedt SC, Dewitte H. Three decades of messenger RNA vaccine development. Nano Today. 2019; 28:100766.

25. Centers for Disease Control and Prevention. Ensuring the safety of COVID-19 vaccines in the United States. https://www.cdc.gov/ coronavirus/2019-ncov/vaccines/safety.html. Accessed 10 May 2021.

26. Shimabukuro T, Nair N. Allergic reactions including anaphylaxis after receipt of the first dose of Pfizer-BioNTech COVID-19 vaccine. JAMA. 2021;325(8):780-1.

27. Centers for Disease Control and Prevention. Interim consideration: preparing for the potential management of anaphylaxis after COVID-19 vaccination. https://www.cdc.gov/vaccines/covid-19/ clinical-considerations/managing-anaphylaxis.html. Accessed 10 May 2021. 
28. Castells MC, Phillips EJ. Maintaining safety with SARS-CoV-2 vaccines. N Engl J Med. 2021;384(7):643-9.

29. Creech CB, Walker SC, Samuels RJ. SARS-CoV-2 vaccines. JAMA. 2021;325(13):1318-20.

30. Centers for Disease Control and Prevention. When you've been fully vaccinated. How to protect yourself and others. https://www. cdc.gov/coronavirus/2019-ncov/vaccines/fully-vaccinated.html. Accessed 10 May 2021.

31. Murai IH, Fernandes AL, Sales LP, Pinto AJ, Goessler KF, Duran CSC, et al. Effect of a single high dose of vitamin D3 on hospital length of stay in patients with moderate to severe COVID-19: A randomized clinical trial. JAMA. 2021;325(11):1053-60.

32. Thomas S, Patel D, Bittel B, Wolski K, Wang Q, Kumar A, et al. Effect of high-dose zinc and ascorbic acid supplementation vs usual care on symptom length and reduction among ambulatory patients with SARS-CoV-2 infection: The COVID A to Z Randomized Clinical Trial. JAMA Netw Open. 2021; 4(2):e210369.

33. US Food and Drug Administration. Why you should not use ivermectin to treat or prevent COVID-19. https://www.fda.gov/ consumers/consumer-updates/why-you-should-not-use-iverm ectin-treat-or-prevent-covid-19\#: :text=FDA\%20has\%20not $\%$ 20approved $\% 20$ ivermectin,and $\% 20$ skin $\% 20$ conditions $\% 20$ like $\%$ 20rosacea. Accessed 10 May 2021.

34. Ontario COVID-19 Science Advisory Table. Risk of vaccineinduced thrombotic thrombocytopenia (VITT) following the AstraZeneca/COVISHIELD adenovirus vector COVID-19 vaccines. Updated May 11, 2021. https://doi.org/10.47326/ocsat. 2021.02.28.1.0. Accessed 15 July 2021.

35. European Medicines Agency. AstraZeneca's COVID-19 vaccine: EMA finds possible link to very rare cases of unusual blood clots with low blood platelets. https://www.ema.europa.eu/en/news/ astrazenecas-covid-19-vaccine-ema-finds-possible-link-very-rarecases-unusual-blood-clots-low-blood. Accessed 15 Jul 2021.

36. Iacobucci G. Covid-19: No evidence that vaccines can affect fertility, says new guidance. BMJ. 2021; 372:n509.

37. Centers for Disease Control and Prevention. COVID-19 vaccines while pregnant or breastfeeding. https://www.cdc.gov/coron avirus/2019-ncov/vaccines/recommendations/pregnancy.html. Accessed 21 May 2021.

38. Kucirka LM, Norton A, Sheffield JS. Severity of COVID-19 in pregnancy: A review of current evidence. Am J Reprod Immunol. 2020; 84(5):e13332.

39. Dashraath P, Wong JLJ, Lim MXK. Coronavirus disease 2019 (COVID-19) pandemic and pregnancy. Am J Obstet Gynecol. 2020;222:521-31.

40. Sentilhes L, De Marcillac F, Jouffrieau C, Kuhn P, Thuet V, Hansmann Y, et al. Coronavirus disease 2019 in pregnancy was associated with maternal morbidity and preterm birth. Am J Obstet Gynecol. 2020;223(6):914.e1-914.e15.

41. Shimabukuro TT, Kim SY, Myers TR, Moro PL, Oduyebo T, Panagiotakopoulos L, et al. Preliminary findings of mRNA Covid-19 vaccine safety in pregnant persons. N Engl J Med. 2021;384(24):2273-82.

42. Gray KJ, Bordt EA, Atyeo C, Deriso E, Akinwunmi B, Young $\mathrm{N}$, et al. Coronavirus disease 2019 vaccine response in pregnant and lactating women: a cohort study. Am J Obstet Gynecol. 2021;S0002-9378(21):00187-93.

Publisher's Note Springer Nature remains neutral with regard to jurisdictional claims in published maps and institutional affiliations. 